\title{
HUBUNGAN PENGETAHUAN DAN SIKAP PENJUAL MAKANAN ONLINE TERHADAP PENGGUNAAN WADAH STYROFOAM DI WONOMULYO.
}

\author{
Elvit Indirawati ${ }^{1,}$ dan Sukmawati ${ }^{2}$, Yuliani Soerachmad ${ }^{3}$ \\ ${ }^{1}$ Kampus Universitas Al Asyariah Mandar, Fakultas Kesehatan Masyarakat. \\ Jl. Budi Utomo No.2 Manding, Kecamatan Polewali, Kabupaten Polewali Mandar, Provinsi Sulawesi \\ Barat, Indonesia. \\ E-mail: Elvit233@gmail.com
}

\section{THE RELATION OF KNOWLEDGE AND THE ATTITUDE OF THE SELLER FOOD ONLINE ON THE USE OF A CONTAINER STYROFOAM IN WONOMULYO}

\begin{abstract}
Styrofoam is materially from polytrene, Remains one of the plastics and is a monomers styrene. Danger monomers styrene on health after exposure in the long run the cause of headaches, tired, depression, anemia, In addition styrofoam waste garbage is very difficult to be unraveled by nature This study aims to analyze the knowledge and attitudes on the use of this is to be a food in food sellers online. The kind of research this is descriptive of analytic with the approach of cross sectional. As for samples to this research is food retailer online the sample of the 49 taken a total of sampling. Data then analyzed by test chi-square with a significant degree $\alpha=0.05$. The results of studies show that there is a connection between knowledge with the use of styrofoam on food vendors online $(\rho=0.036<0.05)$. And there was no correlation between attitude by the use of food in a container styrofoam online $(\rho=0.727>0.05)$. Suggested to the seller online food more attention to container used shall or not as a receptacle for all kinds of food, Especially styrofoam container should be more reduced its use or not be used anymore because ingredient in styrofoam contains a chemical that can move quickly when the food in a hot environment.
\end{abstract}

\begin{abstract}
ABSTRAK
Styrofoam adalah material dari polytrene, masih termasuk golongan plastik dan merupakan sebuah monomer styrene. Bahaya monomer styrene terhadap kesehatan setelah terpapar dalam jangka panjang yaitu menyebabkan sakit kepala, letih, depresi dan anemia selain itu sampah Styrofoam merupakan limbah yang sangat sulit terurai oleh alam. Penelitian ini bertujuan menganalisis hubungan pengetahuan dan sikap terhadap penggunaan Styrofoam sebagai wadah makanan pada penjual makanan online. Jenis penelitian ini adalah deskriptif analitik dengan pendekatan cross sectional. Adapun sampel pada penelitian ini adalah penjual makanan online dengan jumlah sampel 49 yang diambil dengan teknik Total sampling. Data kemudian dianalisis dengan uji Chi-Square dengan tingkat signifikan $\alpha=0,05$. Hasil penelitian menunjukan bahwa terdapat hubungan antara pengetahuan dengan penggunaan Styrofoam pada penjual makanan online ( $\rho=$ $0,036<0,05)$ dan tidak terdapat hubungan antara sikap dengan penggunaan wadah Styrofoam pada penjual makanan online $(\rho=0,727>0,05)$. Disarankan kepada penjual makanan online lebih memperhatikan wadah yang digunakan apakah layak atau tidak sebagai wadah untuk semua jenis makanan, terutama wadah Styrofoam harus lebih dikurangi penggunaannya atau jangan digunakan lagi karena kandungan yang terdapat didalam Styrofoam mengandung zat kimia yang bisa berpindah dengan cepat apabila makanan tersebut dalam keadaan panas.
\end{abstract}

Kata Kunci: Styrofoam, pengetahuan, sikap, penjual makanan online 


\section{PENDAHULUAN}

Salah satu kebutuhan dasar manusia adalah makanan yang pemenuhannya merupakan hak asasi setiap warga masyarakat sehingga harus tersedia dalam jumlah yang cukup, aman, bermutu, bergizi, dan beragam dengan harga yang terjangkau oleh kemampuan daya beli masyarakat. Tersedianya pangan yang aman dan bermutu harus berdasarkan pada suatu standar sehingga tidak membahayakan kesehatan konsumen dan menjamin terselenggaranya perdagangan yang jujur serta bertanggung jawab tanpa membohongi konsumen. ${ }^{1}$

Makanan yang beredar saat ini tidak lepas dari penggunaan wadah/kemasan dengan berbagai tujuan. Dari sisi keamanan makanan, wadah/kemasan makanan bukan sekedar pembungkus tetapi juga sebagai pelindung agar makanan aman dikonsumsi. Namun tidak semua jenis wadah/kemasan makanan aman bagi makanan yang ada didalamnya. Beberapa zat dapat berpindah dari wadah kedalam makanan.

Wadah/kemasan makanan yang berbahan plastik terbuat dari beberapa jenis polimer yaitu Polietilen Tereftalat (PET), Polivinil Clorida (PC), Polietilen (PE), Polipropilen (PP), Polistirena (PS), Polikarbonat (PC) dan Melamin. Diantara kemasan plastik tersebut, salah satu jenis yang cukup populer dikalangan masyarakat produsen maupun konsumen pada saat ini adalah jenis Polistirena, terutama Styrofoam. Styrofoam saat ini menjadi salah satu pilihan yang paling populer dalam bisnis makanan, meskipun oleh pembuatnya.

$$
\text { Perusahaan Dow Chemical }
$$

dimaksudkan untuk digunakan sebagai insulator pada bahan kontruksi bangunan. Kemasan Styrofoam ini dipilih karena mampu mempertahankan makanan yang panas/dingin, tetap nyaman untuk dipegang, mempertahankan keutuhan bahan, biaya murah, dan ringan. Karena kelebihannya tersebut, kemasan Styrofoam digunakan untuk pengemas pangan siap saji, segar, maupun yang memerlukan proses lebih lanjut. ${ }^{2}$

\section{U.S. Environmental Protection Agency} (USEPA) atau Badan Perlindungan Lingkungan Amerika Serikat juga mencatat terdapat 28.500 ton sampah kemasan Styrofoam di New York pada 2014 dan di Amerika Serikat setiap tahun terdapat 25 miliar cangkir kopi Expanded Polystyrene (EPS) atau Styrofoam menjadi sampah. Adapun di Hong Kong, 135 ton sampah Expanded Polystyrene (EPS) atau Styrofoam dibuang ke tempat pembuangan sampah pada 2006. Karena jumlah limbah Expanded Polystyrene (EPS) yang sedemikian besar, dan dampaknya yang ditimbulkan bagi kesehatan atau lingkungan maka banyak beberapa kota/negara seperti Inggris, Oxford, Los Angeles, Seattle, New York, Jepang dan lainnya telah melarang penggunaan Expanded Polystyrene (EPS) atau Styrofoam (BBC, 2015). ${ }^{4}$

Di Ibu Kota Negara Indonesia sendiri, berdasarkan Badan Pusat Statistik (BPS) 2016 
bahwa produksi sampah Provinsi DKI Jakarta mencapai 7.099,08 $\mathrm{m}^{3}$ atau meningkat dari $7.046,39 \mathrm{~m}^{3}$ pada tahun sebelumnya. Namun, hanya $84,7 \%$ dari jumlah sampah tersebut yang bisa terangkut. Sisanya terbuang di alam dan parahnya, sampah yang tak terangkut sebagian mengalir ke laut didominasi oleh Styrofoam dan jenis plastik lainnya. Hal ini tentunya berdampak pada kondisi dan mahluk hidup yang ada di lautan. Contohnya seperti kasus yang baru-baru ini terjadi di Wakatobi, adanya hewan laut yang mati terdampar dan ditemukan sampah $5,9 \mathrm{Kg}$ didalam perut hewan tersebut, sampah tersebut didominasi oleh berbagai sampah berbahan dasar plastik.

Selain Ibu Kota Jakarta, berdasarkan kajian Badan Pengelolaan Lingkungan Hidup (BPLH) Bandung 2016, menyebut bahwa sampah Styrofoam Kota Bandung dapat mencapai 27,02 ton per bulan. Sebab itu Pemerintah Kota Bandung menetapkan kebijakan mengenai larangan penggunaan Styrofoam melalui surat edaran Wali Kota Nomor 658.1/SE.117-BPLH/2016 tentang Penggunaan Kemasan Berbahan Polistirena (PS) Foam atau Styrofoam pada 1 November $2016 .^{5}$

Pada penjualan makanan Online tak terlepas dari wadah/kemasan yang digunakan untuk membungkus makanan. Hasil riset Tetra Pak Index membuktikan bahwa daya tahan dan efisiensi kemasan menjadi persyaratan penting dalam kegiatan menjual/belanja Online. Masyarakat saat ini tidak hanya membeli gadget dan barang fashion secara Online, namun juga sudah mulai membeli makanan olahan atau siap saji secara Online pula. ${ }^{6}$

Berdasarkan observasi awal yang telah dilakukan oleh peneliti diketahui bahwa di Kota Polewali Mandar khususnya di Kecamatan Wonomulyo banyak penjual makanan yang mulai mencoba peruntungan di media Internet/Online dengan memasarkan makanan yang dikemas menggunakan Styrofoam. Dari survei media sosial yang dilakukan peneliti, menemukan bahwa ada $65,3 \%$ penjual makanan Online di Wonomulyo yang menggunakan Styrofoam. Berbagai jenis makanan dikemas dalam wadah Styrofoam seperti mie goreng, mie ayam, siomay, bubur ayam, cokelat panas, gorengan, dan lain-lain. Padahal makananmakanan tersebut tidak boleh dikemas dengan Styrofoam karena mengandung minyak dan lemak. Bahkan tidak jarang Styrofoam digunakan untuk membungkus makanan yang baru selesai dimasak dan masih panas.

Tujuan dari penelitian ini yaitu untuk mengetahui hubungan pengetahuan dan sikap terhadap penggunaan wadah Styrofoam pada penjual makanan Online di Kecamatan Wonomulyo.

\section{BAHAN DAN METODE}

Jenis dari penelitian yaitu survei yang bersifat deskriptif analitik, yang dilakukan di Kecamatan Wonomulyo Kabupaten Polewali Mandar pada 16 Februari - 13 Maret 2019. Sampel pada penelitian ini adalah 49 orang, 
yang terdiri dari penjual makanan online yang menggunakan styrofoam dan yang tidak menggunakan styrofoam di Kecamatan Wonomulyo. Teknik pengambilan sampel yaitu dengan menggunakan teknik total sampling.

Pengumpulan data dalam penelitian ini dengan melakukan wawancara menggunakan kuesioner, yang terlebih dahulu meminta responden untuk menanda tangani lembar informed concent sebagai bukti persetujuan responden bersedia menjadi subyek dalam penelitian. Pada penelitian ini menggunakan sumber data primer dan sekunder dan pengolahan data dilakukan dengan menggunakan program Statistical Product and Service Solutions 21 (SPSS) dengan melakukan analisis univariat setiap variabel dan analisis Bivariat untuk mengetahui hubungan variabel dependen dan independen.

\section{HASIL \\ Karakteristik Responden}

Karakteristik umum dalam penelitian ini mencakup jenis kelamin, umur dan pendidikan responden yaitu para penjual makanan Online.

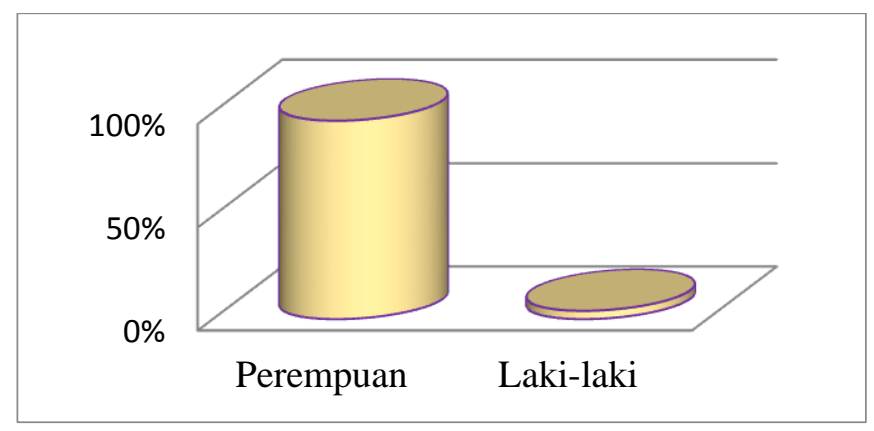

Gambar 1. Distribusi Frekuensi Responden Berdasarkan Jenis Kelamin

Berdasarkan gambar 1 menunjukan sedikit yaitu 2 orang $(4,1 \%)$ dan yang berjenis bahwa jumlah responden penjual makanan kelamin perempuan lebih banyak yaitu 47 Online yang berjenis kelamin laki-laki lebih orang $(95,9 \%)$.

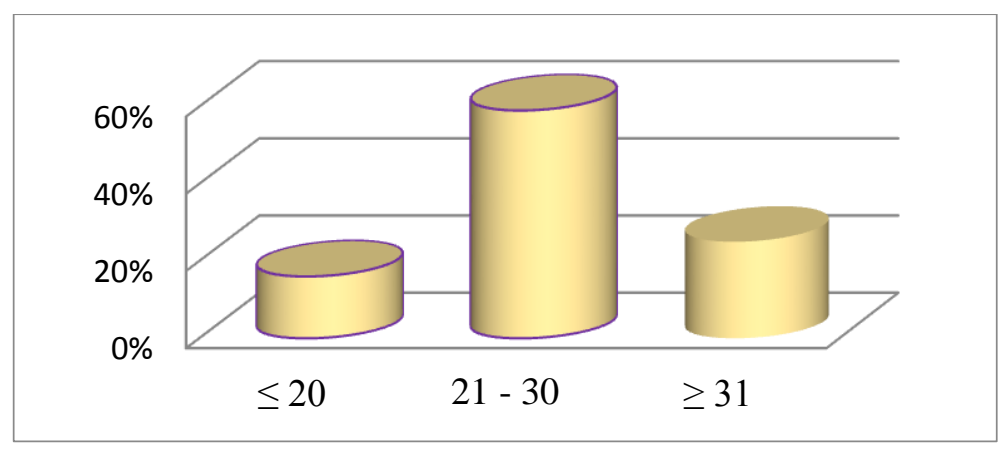

Gambar 2. Distribusi Frekuensi Responden Berdasarkan Umur 
Berdasarkan gambar 2 menyatakan jumlah responden penjual makanan Online yang berumur $\geq 31$ tahun yaitu 12 orang $(24,5 \%)$, sedangkan yang berumur $\leq 20$ tahun yaitu sebanyak 8 orang $(16,3 \%)$, dan yang berumur 21-30 tahun lebih banyak yaitu 29 orang $(59,2 \%)$.

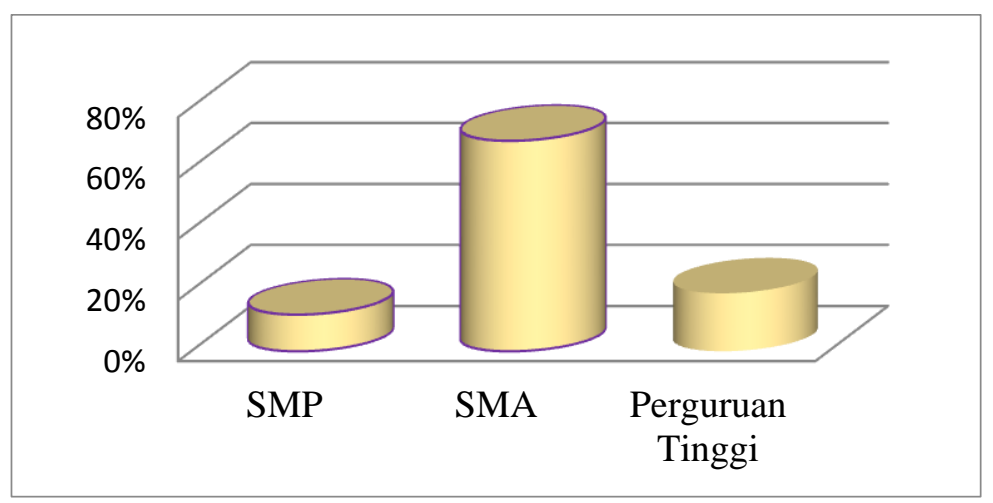

Gambar 3. Distribusi Frekuensi Responden Berdasarkan Pendidikan

Berdasarkan gambar diatas menunjukan bahwa jumlah responden penjual makanan Online yang berpendidikan SMP lebih sedikit yaitu 6 orang $(12,2 \%)$, sedangkan yang tamat perguruan tinggi yaitu sebanyak 9 orang $(18,4 \%)$, dan yang paling banyak adalah yang berpendidikan SMA yaitu sebanyak 34 orang $(69,4 \%)$.

\section{Analisis Univariat Variabel Penelitian}

Tabel 1. Distribusi Frekuensi Responden Berdasarkan Variabel Penelitian

\begin{tabular}{llcc}
\hline No. & Variabel Penelitian & $\mathrm{n}$ & $\%$ \\
\hline \multirow{2}{*}{1} & Penggunaan Styrofoam & & \\
& Menggunakan & 32 & 65,3 \\
& Tidak Menggunakan & 17 & 34,7 \\
\hline \multirow{2}{*}{2} & Pengetahuan & & \\
& Cukup & 19 & 38,8 \\
& Kurang & 30 & 61,2 \\
\hline \multirow{2}{*}{3} & Sikap & 39 & 79,6 \\
& Baik & 10 & 20,4 \\
\cline { 2 - 3 } & Buruk & & 100 \\
\cline { 2 - 3 }
\end{tabular}

Sumber : Data Primer, 2019.

Berdasarkan tabel diatas menunjukan bahwa jumlah responden penjual makanan Online, yang menggunakan Styrofoam lebih banyak yaitu 32 orang $(65,3 \%)$ dan yang tidak menggunakan Styrofoam 17 orang (34,7\%).
Kemudian untuk tingkat pengetahuan penjual makanan Online, yang memiliki pengetahuan kurang tentang penggunaan wadah Styrofoam lebih banyak yaitu 30 orang $(61,2 \%)$ dan yang memiliki pengetahuan cukup sebanyak 19 
orang $(38,8 \%)$. Selanjutnya untuk responden penjual makanan Online yang memiliki sikap baik terhadap penggunaan wadah Styrofoam Analisis Bivariat Hubungan Antar Variabel

Tabel 4. Analisis Hubungan Pengetahuan dan Sikap Terhadap Penggunaan Styrofoam Pada Penjual Makanan Online

\begin{tabular}{|c|c|c|c|c|c|c|c|c|}
\hline \multirow{3}{*}{ No } & \multirow{3}{*}{$\begin{array}{c}\text { Variabel } \\
\text { Independen }\end{array}$} & \multicolumn{4}{|c|}{ Variabel Dependen } & \multirow{2}{*}{\multicolumn{2}{|c|}{ Total }} & \multirow{3}{*}{$P$ Value } \\
\hline & & \multicolumn{4}{|c|}{ Penggunaan Styrofoam } & & & \\
\hline & & \multicolumn{2}{|c|}{ Tidak Menggunakan } & \multicolumn{2}{|c|}{ Menggunakan } & & & \\
\hline \multirow{4}{*}{1} & Pengetahuan & $\mathrm{n}$ & $\%$ & $\mathrm{n}$ & $\%$ & $\mathrm{n}$ & $\%$ & \multirow[t]{4}{*}{0,036} \\
\hline & Kurang & 7 & 41,1 & 23 & 71,8 & 30 & 61,2 & \\
\hline & Cukup & 10 & 58,9 & 9 & 28,2 & 19 & 38,8 & \\
\hline & Jumlah & 17 & 34,7 & 32 & 65,3 & 49 & 100 & \\
\hline \multirow[t]{4}{*}{2} & Sikap & & & & & & & \multirow[t]{4}{*}{0,727} \\
\hline & Buruk & 3 & 17,6 & 7 & 21,8 & 10 & 20,5 & \\
\hline & Baik & 14 & 82,4 & 25 & 78,2 & 39 & 79,5 & \\
\hline & Jumlah & 17 & 34,7 & 32 & 65,3 & 49 & 100 & \\
\hline
\end{tabular}

Sumber : Data Primer, 2019.

Dari tabel diatas dapat diketahui bahwa penjual makanan Online yang memiliki pengetahuan kurang dengan tidak menggunakan Styrofoam sebagai wadah makanan sebanyak 7 orang $(41,1 \%)$. Dan penjual makanan Online yang memiliki pengetahuan cukup dengan tidak menggunakan Styrofoam sebanyak 10 orang (58,9\%). Sedangkan, penjual makanan Online yang memilki pengetahuan kurang dengan menggunakan Styrofoam sebagai wadah makanan sebanyak 23 orang $(71,8 \%)$ dan yang memiliki pengetahuan cukup dengan menggunakan Styrofoam sebagai wadah makanan sebanyak 9 orang $(28,2 \%)$. Berdasarkan hasil uji statistik yang dilakukan dengan Chi-Square maka didapatkan hasil yaitu 39 orang $(79,6 \%)$ dan yang memiliki sikap buruk yaitu 10 orang $(20,4 \%)$ 
sikap baik dengan menggunakan Styrofoam sebagai wadah makanan sebanyak 25 orang $(78,2 \%)$.

Berdasarkan hasil uji statistik yang dilakukan dengan uji Chi-Square, maka diperoleh hasil bahwa $\mathrm{HO}$ diterima dan $\mathrm{Ha}$ ditolak dengan hasil $p$ value $0,727>p$ value 0,05 yang berarti tidak ada hubungan antara sikap penjual makanan Online dengan penggunaan Styrofoam sebagai wadah makanan.

\section{PEMBAHASAN}

Analisis Hubungan Tingkat Pengetahuan Penjual Makanan Online dengan Penggunaan Styrofoam sebagai Wadah Makanan di Kecamatan Wonomulyo

Pada analisis hubungan pengetahuan dapat dilihat bahwa hasil analisis yang menggunakan Chi-Square mendapatkan hasil bahwa penjual makanan Online yang memiliki pengetahuan kurang dengan tidak menggunakan Styrofoam sebagai wadah makanan sebanyak 41,1\%. Dan penjual makanan Online yang memiliki pengetahuan cukup dengan tidak menggunakan Styrofoam sebanyak $58,9 \%$.

Sedangkan, penjual makanan Online yang memilki pengetahuan kurang dengan menggunakan Styrofoam sebagai wadah makanan sebanyak $71,8 \%$ dan yang memiliki pengetahuan cukup dengan menggunakan Styrofoam sebagai wadah makanan sebanyak $28,2 \%$. Uji tersebut mendapatkan nilai $p$ value $0,036<p$ value 0,05 yang berarti ada hubungan antara pengetahuan penjual makanan Online dengan penggunaan Styrofoam sebagai wadah makanan.

Namun, hasil penelitian ini tidak sejalan dengan penelitian yang dilakukan oleh Ela, Rochmawati dan Selviana (2016) tentang faktor yang berhubungan penggunaan wadah Styrofoam sebagai kemasan makanan pada penjual makanan jajanan di kota Pontianak, menyatakan bahwa tidak ada hubungan antara pengetahuan dengan penggunaan wadah Styrofoam sebagai kemasan makanan.

Tetapi penelitian ini sejalan dengan penelitian yang dilakukan oleh Abidin, (2016) tentang hubungan pengetahuan dan sikap penjamah makanan kapal penumpang terhadap penggunaan Styrofoam sebagai wadah makanan di pelabuhan Makassar. Dengan hasil penelitiannya menunjukkan bahwa ada hubungan pengetahuan responden dengan penggunaan Styrofoam sebagai wadah makanan, yang diuji dengan Fisher's Exact Test menunjukan angka signifikan $(p)$ 0,004.

Selain itu pada penelitian ini yang respondennya adalah penjual makanan Online, dari hasil analisis masih menemukan bahwa ada 9 orang $(28,2 \%)$ yang memiliki pengetahuan cukup mengenai Styrofoam tapi responden tersebut masih melakukan tindakan dengan menggunakan wadah makanan Styrofoam, padahal seharusnya jika responden memiliki pengetahuan yang cukup maka 
responden akan memiliki tindakan dengan tidak lagi menggunakan wadah Styrofoam, tetapi hal ini terjadi sebaliknya.

Hal tersebut menunjukkan bahwa menggunakan atau tidak menggunakan Styrofoam sebagai wadah makanan, belum tentu hanya dikarenakan oleh faktor cukup atau kurangnya pengetahuan penjual makanan Online. Begitu pula dengan cukup atau kurangnya pengetahuan tentang wadah Styrofoam pada penjual makanan Online, belum tentu karna responden tersebut menggunakan atau tidak menggunakan wadah Styrofoam. Hal ini dapat terjadi karena pengetahuan bukanlah satu-satunya faktor pembentuk tindakan seseorang, dan tindakan bukan juga satu-satunya faktor pembentuk pengetahuan seseorang.

Hal tersebut sesuai dengan pernyataan World Health Organization (WHO) yang menyebutkan bahwa perilaku, dalam hal ini tindakan, terbentuk oleh beberapa faktor, yaitu pikiran dan perasaan, orang yang berarti (panutan), sumber daya, dan budaya. Pikiran dan perasaan dibentuk oleh pengetahuan, kepercayaan, sikap, dan nilai yang dimiliki. Pengetahuan dapat berasal dari pengalaman yang dimiliki seseorang ataupun informasi dari sumber lain yang lebih tahu, seperti guru, orang tua, teman, buku, majalah, dan lainnya. Hal serupa juga dikemukakan oleh teori Green dimana perilaku terbentuk atas 3 faktor utama yaitu faktor predisposisi, faktor pemungkin, dan faktor penguat. Faktor predisposisi mencakup pengetahuan dan sikap masyarakat, tradisi dan kepercayaan masyarakat terhadap hal yang berkaitan, sistem nilai yang dianut masyarakat, tingkat pendidikan, dan tingkat sosial ekonomi. Faktor pemungkin meliputi ketersediaan sarana dan prasarana bagi masyarakat. Sikap dan perilaku tokoh yang disegani menjadi faktor penguat terbentuknya perilaku (Notoatmodjo, 2007).

Dan sekali lagi banyak faktor lain yang mempengaruhi pengetahuan seperti adanya faktor umur, Intelegensi seseorang, lingkungan, sosial budaya, informasi yang diterima, pendidikan dan pengalaman seseorang. Kemudian dalam penelitian ini juga mendapatkan bahwa masih ada responden yang sudah memiliki pengetahuan cukup tentang penggunaan wadah Styrofoam tetapi masih menggunakan wadah Styrofoam, berdasarkan wawancara saat penelitian beberapa responden juga mengaku bahwa alasan menggunakan wadah Styrofoam sebagai kemasan makanan dikarenakan alasan harganya yang murah dan penggunaannya yang mudah/praktis.

\section{Analisis Hubungan Sikap Penjual Makanan \\ Online dengan Penggunaan Styrofoam sebagai Wadah Makanan di Kecamatan Wonomulyo}

Hasil analisis menggunakan uji ChiSquare dengan program Statistical Product And Service Solutions 21 (SPSS), hasilnya 
dapat dilihat pada Tabel diatas yang memperlihatkan bahwa penjual makanan Online yang memiliki sikap buruk dan tidak menggunakan Styrofoam sebagai wadah makanan yaitu sebanyak 17,6\%. Kemudian pada penjual makanan Online yang memiliki sikap baik dan tidak menggunakan wadah Styrofoam sebanyak 82,4\%. Sedangkan, penjual makanan Online yang memilki sikap buruk dan menggunakan Styrofoam sebagai wadah makanan yaitu sebanyak $21,8 \%$ dan yang memiliki sikap baik dengan menggunakan Styrofoam sebagai wadah makanan yaitu sebanyak 78,2\%. Uji ChiSquare dengan program Statistical Product And Service Solutions 21 (SPSS) tersebut menghasilkan $p$ value 0,727 yang berarti nilai ini lebih besar dari $p$ value 0,05 jadi berdasarkan nilai $p$ value dapat dinyatakan bahwa tidak ada hubungan antara sikap penjual makanan Online dengan penggunaan Styrofoam sebagai wadah makanan.

Dan hasil penelitian ini sejalan dengan hasil penelitian dari Urwatil Wusqa Abidin, (2016) tentang hubungan pengetahuan dan sikap penjamah makanan kapal penumpang terhadap penggunaan Styrofoam sebagai wadah makanan di pelabuhan Makassar. Dengan hasil penelitiannya menunjukkan bahwa tidak ada hubungan sikap responden dengan penggunaan Styrofoam sebagai wadah makanan, yang diuji dengan uji Fisher's Exact Test program Statistical Product And Service Solutions
(SPSS) menunjukan angka signifikan $p$ value 0,118 .

Sikap lebih sering disebut sebagai respon tertutup dari individu. Dalam teori psikologi (Dayakisni dan Hudaniah, 2003) bahwa sikap merupakan suatu keaadaan (respon tertutup individu) yang memungkinkan untuk timbulnya suatu perbuatan atau tingkah laku. Menurut Sarlito (2009), menyatakan bahwa individu memiliki sikap positif ketika individu mampu menerima, menghargai, dan bertanggung jawab terhadap stimulus dan menghasilkan tindakan yang positif pula (Udin, 2012).

Hasil penelitian pada penjual makanan Online tentang sikap terhadap penggunaan wadah Styrofoam menunjukan jumlah yang tidak signifikan antara sikap baik dengan penggunaan wadah Styrofoam sebagai tempat makanan. Sudah dijelaskan diatas bahwa pada analisis yang telah dilakukan dengan program Statistical Product And Service Solutions 21 (SPSS) mendapatkan sebanyak $25 \quad(78,2 \%)$ responden mempunyai sikap (respon tertutup individu) yang baik tetapi masih menggunakan wadah Styrofoam untuk makanannya, padahal seharusnya sesuai teori yang dikemukakan oleh Sarlito (2009) bahwa jika individu memiliki sikap positif maka akan menghasilkan suatu tindakan yang positif pula.

Jadi hasil analisis bivariat dengan program Statistical Product And Service Solutions 21 (SPSS), tentang hubungan sikap 
terhadap penggunaan wadah Styrofoam pada penelitian ini seharusnya menghasilkan $p$ value $<0,05$ yang menyatakan ada hubungan antara sikap dengan penggunaan wadah Styrofoam sebagai tempat makanan. Sedangkan pada penelitian kali ini menolak teori tersebut, dan menyatakan keterbalikan dari teori yang dikemukaan oleh Sarlito (2009), menjadi sebuah teori baru bahwa suatu sikap yang positif belum tentu menghasilkan tindakan yang positif pula dalam hal ini penggunaan wadah Styrofoam sebagai kemasan makanan yang dijual oleh penjual makanan Online.

Pada penelitian ini mendapatkan nilai $p$ $>0,05$ yaitu 0,727 yang artinya menyatakan bahwa tidak ada hubungan yang signifikan antara sikap penjual makanan Online dengan penggunaan wadah makanan Styrofoam. Hasil penelitian ini membuktikan bahwa tidak selamanya tindakan seseorang, dalam hal ini penggunaan wadah Styrofoam selalu berbanding lurus dengan sikapnya.

Hal seperti ini bisa terjadi dikarenakan ada beberapa faktor atau variabel lain yang mempengaruhi sikap dan tindakan/perilaku seseorang, dalam hal ini penggunaan wadah Styrofoam pada penjual makanan Online. Faktor-faktor tersebut atau variabel yang berpegaruh itu tidak termasuk variabel yang diteliti pada penelitian ini, seperti adanya faktor modal atau ekonomi yang dimiliki responden atau penjual makanan Online. Kemudian adanya faktor terjangkaunya harga wadah makanan Styrofoam di pasaran. Hal inipun disampaikan oleh beberapa responden dalam wawancara saat penelitian dengan menggunakan kuisioner bahwa jika responden hanya memiliki modal sedikit, mau tidak mau maka responden atau penjual makanan Online mencari wadah makanan yang relatif lebih murah dan terjangkau seperti wadah Styrofoam. Dan memang harga wadah Styrofoam dipasaran sangat terjangkau dibanding dengan harga kemasan lainnya yaitu 200-300 rupiah sudah mendapatkan 1 (satu) wadah Styrofoam atau dengan Rp. 25.000 saja sudah mendapatkan 100 pcs/buah wadah Styrofoam untuk kemasan makanan dengan ukuran sedang.

Selain faktor atau variabel tersebut beberapa responden atau penjual Online mengatakan bahwa meskipun mengetahui dampak dari wadah Styrofoam pada makanan ataupun lingkungan sekitar, namun faktor kemudahan/praktisnya dalam penggunaan serta ketahanan waah Styrofoam terhadap suhu makanan, membuat responden atau penjual makanan Online tetap membeli atau menggunakan wadah Styrofoam tersebut sebagai wadah makanan untuk jualan mereka.

\section{KESIMPULAN}

Sebagian besar responden penjual makanan online memiliki pengetahuan kurang tentang penggunaan wadah Styrofoam yaitu 30 orang $(61,2 \%)$. Berdasarkan data tersebut, hanya sebagian kecil penjual makanan online 
yang memiliki pengetahuan cukup yaitu 19 orang $(38,8 \%)$. Kemudian berdasarkan uji ChiSquare menyatakan bahwa ada hubungan yang signifikan antara pengetahuan penjual makanan online dengan penggunaan Styrofoam sebagai wadah makanan. Hal ini berdasarkan hasil ChiSquare didapatkan $p$ value 0,036 <0,05.

Dari analisis data pada penelitian ini ditemukan juga bahwa sebagian besar responden penjual makanan online memiliki memiliki sikap yang baik terhadap penggunaan wadah Styrofoam yaitu 39 orang (79,6\%). Dan berdasarkan uji statistik yang dilakukan dengan uji Chi-Square, maka diperoleh hasil bahwa $\mathrm{HO}$ diterima dan Ha ditolak dengan hasil nilai $p$ value 0,727>0,05 yang berarti tidak ada hubungan antara sikap penjual makanan online dengan penggunaan Styrofoam sebagai wadah makanan.

\section{SARAN}

Bagi penjual makanan online harus lebih memperhatikan wadah makanan yang digunakan, apakah layak atau tidak digunakan sebagai wadah makanan untuk semua jenis makanan terutama kemasan Styrofoam harus lebih dikurangi penggunaannya. Lebih baik menggunakan kotak makanan yang sudah food grade sebagai wadah makanan. Selain itu, lebih meningkatkkan pengetahuan tentang kemasan yang dibolehkan untuk digunakan sebagai wadah kemasan makanan terutama tentang wadah Styrofoam.

\section{UCAPAN TERIMA KASIH}

Terima kasih kepada kedua orang tua dan keluarga yang memberikan seluruh bantuan dan dukungan dalam menyelesaikan penelitian ini. Serta Camat Wonomulyo yang telah memberikan izi untuk penelitian ini.

\section{DAFTAR PUSTAKA}

1. Badan Pengawas Obat dan Makanan Republika Indonesia. Kemasan Plastik. InfoPOM. 2017. Vol. 18, No. 3 (Online). Diakses 22 November 2018.

2. Badan Pengawas Obat dan Makanan Republika Indone Kemasan Polistirena Foam (Styrofoam). InfoPOM. 20 Vol. 9, No. 5 (Online). Diakses 22 November 2018.

3. Badan Pusat Statistik Provinsi DKI Jakarta. Statistik Air Bersih DKI Jakarta. BPS DKI Jakarta. 2016. (https://jakarta.bps.go.id). (Online). Diakses 22 November 2018.

4. BBC News Indonesia.2015. Kota Oxford Larang Kemasan Makanan Styrofoam. (Online).(https://www.bbc.com/indonesia/ majalah/2015/04/150414oxfordstyrofoam). Diakses 22 November 2018.

5. Ela, Rochmawati, dan Selviana. 2016. Faktor-Faktor yang Mempengaruhi Penggunaan Wadah Styrofoam sebagai Kemasan Makanan pada Penjual Makanan Jajanan di Kota Pontianak.(online). (http://open jurnal. unmuhpnk.ac.id) Diakses 5 November 2018.

6. Pejabat Pengelola Informasi dan Dokumentasi Kota Bandung. 2016. Selamat Tinggal Styrofoam. PPID Bandung. (https://ppid.bandung.go.id/selamattinggal-styrofoam/). (Online). Diakses 25 November 2018.

7. Kurniawan, Anto. 2018. Tetra pak Index 2018 Paparkan Tren Belanja Konsumen di Indonesia.

(Online). (https://ekbis.sindonews.com/read/1335993 134/tetra-pak-index-2018-paparkan-trenbelanja-konsumen-di-indonesia- 
1536156512) Diakses pada 29 November 2018

8. Hendra, AW. 2008. Faktor-Faktor yang Mempengaruhi Pengetahuan. Pustaka Sinar Harapan. Jakarta

9. Kurnia Putra, udin. 2012. Hubungan Tingkat Pengetahuan dan Sikap dengan Perilaku Penggunaan Alat Pelindung Diri pada Mahasiswa Profesi Keperawatan.(online).

(htps://jurnal.ui.ac.id) Diakses 20 maret 2019

10. Notoadmodjo, Soekidjo. 2007. Promosi Kesehatan dan Ilmu Perilaku. Rineka Cipta. Jakarta

11. Rahmadhani, Putri, Fitri Ardiani dan Etti Sudaryati. 2015. Gambaran Pengetahuan dan Sikap dengan Posisi Tawar Konsumen tentang Penggunaan Kemasan Styrofoam sebagai Wadah Makanan di Amaliun Foodcourt. Jurnal Kesehatan Masyarakat (online). htps://jurnal.usu.ac.id) Diakses 5 November 2018. 